\title{
An example of a vine-physiology based fine-scale terroir study in the AOC Lavaux-region in Switzerland
}

\author{
Markus RIENTH ${ }^{1} *$, Frederic LAMY ${ }^{1}$, Dorothea NOLL ${ }^{1}$, Fabrice LORENZINI ${ }^{2}$, Olivier VIRET ${ }^{4}$ and Vivian \\ ZUFFEREY ${ }^{3}$, \\ ${ }^{1}$ CHANGINS, haute ecole de viticulture et œnologie, route de Duillier 60, 1260 Nyon, Switzerland \\ ${ }^{2}$ Agroscope, route de Duillier 50, 1260 Nyon, Switzerland \\ ${ }^{3}$ Agroscope, avenue Rochettaz 21, 1009 Pully, Switzerland \\ ${ }^{4}$ Service de l'agriculture et de la viticulture (SAVI), Avenue de Marcelin 29, 1110 Morges, Switzerland
}

\author{
*Corresponding author: M. Rienth: markus.rienth@changins.ch
}

Key words : terroir, vine physiology, steep slope viticulture, AOC Lavaux, Villette, Chasselas

\begin{abstract}
The aim of this ongoing study is to establish a vine physiology, berry quality - based methodology to analyze small scale differences between plots in a sub-region of the AOC Lavaux, in Switzerland. The production area Villette is almost to $100 \%$ planted with the cultivar Chasselas L. covering a total of 140 ha of steep slope terraced vineyards and offers an excellent site for terroir studies. A representative network of 23 plots covering the entire Villette production area was established in 2016 and 2017. Important differences in budburst and flowering were observed between plots whereas altitude was the main driver of precociousness. Expectedly most precious plots had highest sugar and lowest malic acid concentrations at final sampling date. Individual berry weight variation was up to $35 \%$ at the last sampling ( 2.4 to $3.3 \mathrm{~g})$ with variation in sugar concentration of $13 \%\left(70-84^{\circ}\right.$ Oechsle). Sugar quantity per berry variation was however twice as high $(26 \%)$, illustrating important differences in the sugar accumulation pattern between plots. Interestingly the latest plots accumulated highest sugar per berry with lowest concentration. The preliminary results of this ongoing study provide valuable information of the ripening potential of Chasselas in a small mesoclimate and illustrates the possibilities to characterize viticultural terroirs based on vine physiology measurements.
\end{abstract}

Introduction

Terroir is the interaction of soil, plant and climate in combination with the socioeconomic history of a given region (Leeuwen \& Seguin 2006, Anderson et al. 2012, Tomasi et al. 2013). Plenty of terroir studies have been conducted in different growing regions, focusing of different aspects of the latter equation. In most studies, including plant physiology, a correlation between moderate water deficit and terroir perception could have been shown, which illustrates the importance of vine physiology on terroir perception (van Leeuwen et al. 2009, Reynard et al. 2011). In Switzerland several terroir studies were conducted in most regions in recent years focusing in particular on pedoclimatic characteristics reveailing a huge diversity in soils mainly originating from glacier moraines.(Letessier \& Marion 2007).

A recent study conducted in the canton Vaud $(3800$ ha) considered 10 varieties in a total of 130 microplots, providing important information on cultivar adaptation to different sites on a relatively large scale considering the small structure of Swiss viticulture. A main conclusion of this terroir study was as well that water relations play a crucial role in terroir perception by their influence on vine physiology (Zufferey et al. 2008)

The latter study paved the way for more fine-scale mapping of different growing regions in the future, which seems necessary to better valorize the high diversity of terroirs encountered in Switzerland. 
The most planted white wine variety $(>60 \%)$, Chasselas, documented in the lake of Geneva's area since thousands of years, plays a central role in Swiss viticulture terroirs. One of the most emblematic Chasselas region is the AOC Lavaux (736 ha), where vines are planted in terraces on steep slopes over the lake of Geneva on different altitudes and expositions. Steep slope viticulture in this area is not or very little mechanizable and therefore production costs are very high which threatens the sustainability of small wine producers. To maintain this viticulture patrimony, established by the monks in the $11^{\text {th }}$ century, it is crucial to render consumers aware of the uniqueness of such regions. The aim of this study is to establish a vine physiology, berry quality - based methodology to analyze small scale differences between plots in a sub-region of Lavaux, the production area Villette, in order to better valorize such terroirs.

\section{Material and Methods}

A network of 23 plots covering the whole Villette production area was established in 2016 and completed in 2017 (Figure 1)

All selected plots are planted with the cultivar Chasselas L. on rootstock 3309C, guyot-pruned and trained in a vertical shoot positioning system, with vine age ranging from 15 to 25 years.

In all 23 plots, main phenology stages such as budburst, flowering, véraison and harvest were recorded throughout the season. Berry development was followed on a weekly basis on a 300 berry sample, starting two weeks before véraison. Average berry weight, sugars, tartaric and malic acid were determined by FTIR analysis. Vine vegetative growth was characterized by chlorophyll content of leaves, total exposed leaf area, delta ${ }^{13} \mathrm{C}$ determination in berries and pruning weight.
Exposition, altidue and inclination were calculated with QGIS 2.18.14® (2m precision). Plots were located on an elevation gradient from 380 to $600 \mathrm{~m}$ asl (Figure 2). Calculation of potential intercepted solar radiation between $1^{\text {st }}$ april and $30^{\text {th }}$ September (2m precision) ArcGIS 10.2 - solar Anaylst $(\circledR$ (Figure 3).

Principal component analysis and hierarchical clustering was performed using the $\mathrm{R}$ package FactoMinR ${ }^{\circledR}$. Curve fitting for berry development was performed with Origin pro $2016 \AA$.

Results and discussion

Results of principal component analysis on vegetative (pruning weight, delta ${ }^{13} \mathrm{C}, \mathrm{N}$-tester), reproductive (sugar concentration in ${ }^{\circ}$ Oechsle, extract, malic and tartaric acid) and geophysical data (potential radiation, altitude, inclination) are shown in figure 2. The first-dimension accounting for $27 \%$ of the variation between plots was positively correlated with altitude, day of budburst and flowering as well as individual berry weight, all latter parameters were negatively correlated with sugar concentration ( ${ }^{\circ}$ Oechsle). This can mainly be explained by temperature decrease with increasing altitude which delayed budburst and flowering, and thus the onset of ripening which switched sugar accumulation to cooler periods (Burgos et al. 2010). Interestingly individual berry weight was higher in later ripening plots. The second dimension of the PCA accounting for only $17 \%$ of variation between plots is dominated by potential maximal radiation exposed leaf area and negatively with tartaric acid and inclination. According to delta ${ }^{13} \mathrm{C}$ analysis no water deficit occurred in 2017 thus this variable does not contribute to a high extent to plot variability.

Hierarchical clustering was performed on PCA results and enabled the grouping of plots in three well distinguished clusters based on total inertia. 
Cluster 1 comprises the plots with highest sugar concentration, mainly explained by highest potential radiation but as well characterized by lowest pruning weight thus less vigor's and a relatively high ELA / kg. Main variables explaining the grouping of plots to Cluster 2 are lower altitude and thus preciousness of budburst, flowering and ripening. Cluster 3 regroups the latest ripening plots, primarily due to their higher altitude.

Since sugar concentration is still amongst the most important ripeness indicators and of utmost importance notably in septentrional winegrowing regions such as Switzerland, kinetics of sugar concentration ( ${ }^{\circ}$ Oechsle) evolution and sugar accumulation during berry development were analyzed separately (Figure 5A and B). A continues increase in all plots of sugar concentration ( ${ }^{\circ}$ Oechsle) was observed until harvest with a variation of around $13 \%$ between highest and lowest plots at the last sampling date (70 to 84 ${ }^{\circ}$ Oechsle). Quadratic (order 2) polynomial regression models described best the evolution of sugar concentration. Interestingly regarding sugar quantity per berry a much higher variation of $26 \%$ was observed in combination with a very different accumulation pattern, indicated by the best fitting curves, all polynomial fits of order 4 . This is due to the cessation of phloem sugar unloading in the berry and shows that a subsequent increase in sugar concentration during the late ripening is only due to environmental factors in precious plots.

In plots with highest sugar concentration at harvest sugar accumulation ceased very early during the season, in some plots already at the $5^{\text {th }}$ sampling date (ex. plot 23 and 22) thus further concentration is due to water loss of the berry most likely by transpiration through the berry skin or potentially by waterbacklow in the xylem, which is however less likely (Bondada et al. 2005, Keller et al. 2006). In plots where the onset of ripening was late, phloem unloading stopped right before harvest or not at all according to figure 5B. Such late plots had also the highest individual berry weight (Figure 4 A). Maybe due to the ripening phase that occurred during a cooler period, thus less respiration losses of the vines could have favored / extended berry growth and sugar accumulation. It could as well be hypothesized that due to later budbreak and flowering of late plots cell size as the main factor influencing final berry size and determined very early during the first green growth phase before véraison, was favored by warmer temperatures and/or a higher water availability in late spring / early summer (Ojeda et al. 2001, Diakou-Verdin et al. 2002). Anyhow, such hypothesis needs to be confirmed in subsequent years.

Conclusion

Intermediate results presented in the paper demonstrate the potential to use vine physiology and berry quality to characterize viticulturally terroirs on a very small scale in a pretty similar mesoclimate. Differences between plots in regard to precociousness and thus sugar concentration at harvest due to pedoclimatic differences, in particular altitude could be highlighted which will be of valuable information for growers in view of global warming.

Results on berry sugar accumulation gave interesting insights regarding berry developmental characteristics that are not fully understood by the scientific community up to now, mainly the impact of genotypic versus environmental factors. 


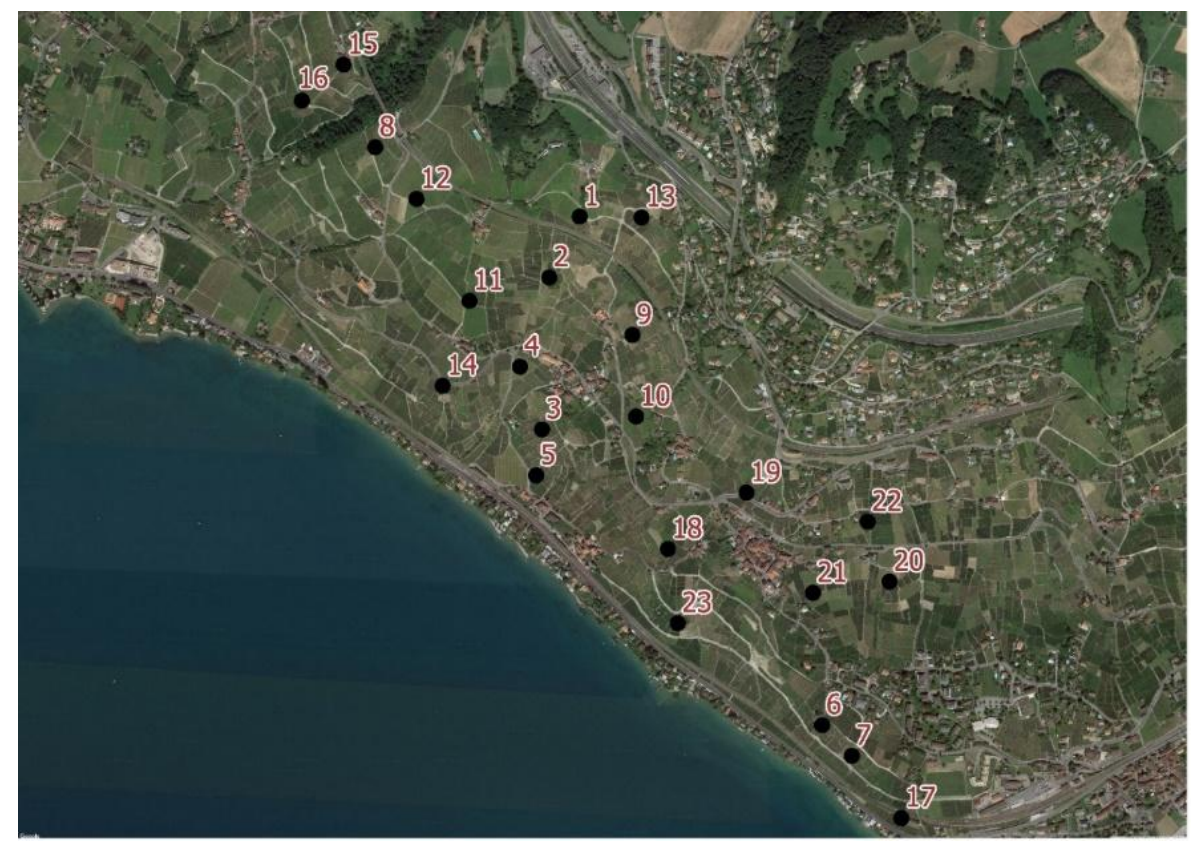

Figure 1 - Localization of Chasselas plots in the Villette production area

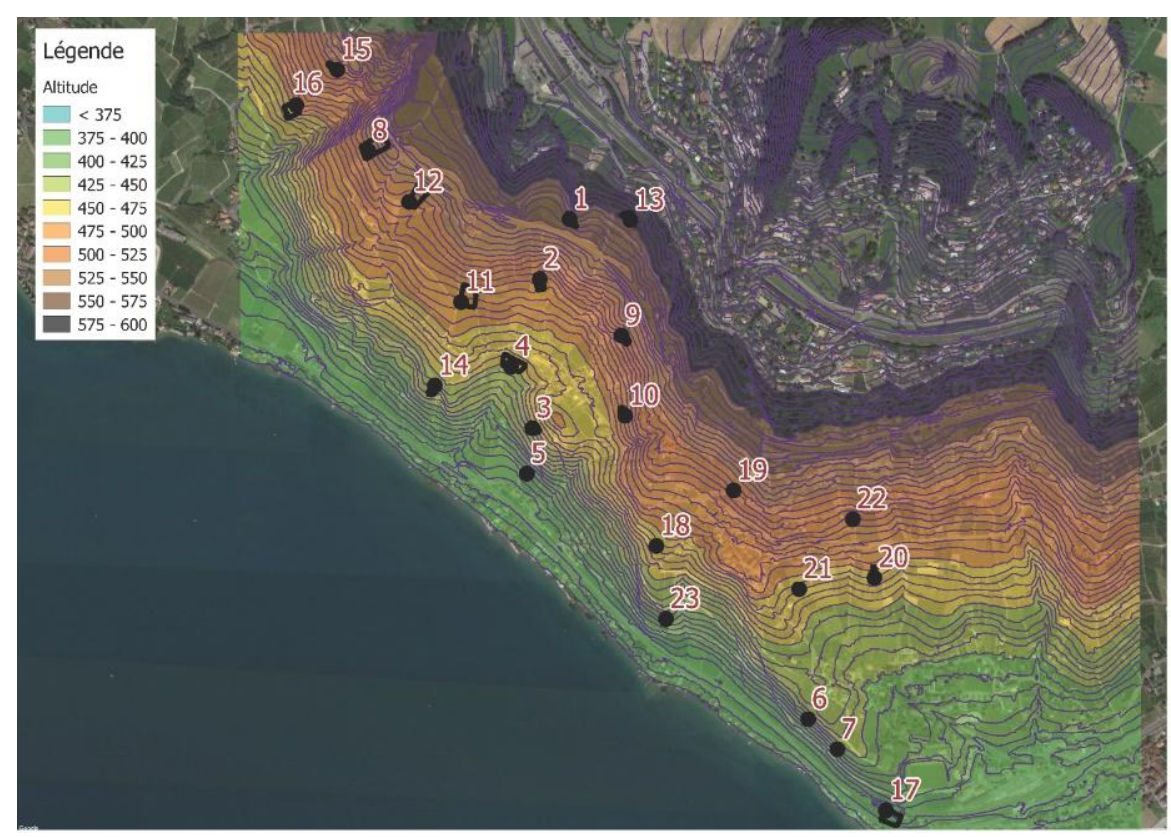

Figure 2 - Altitude map 


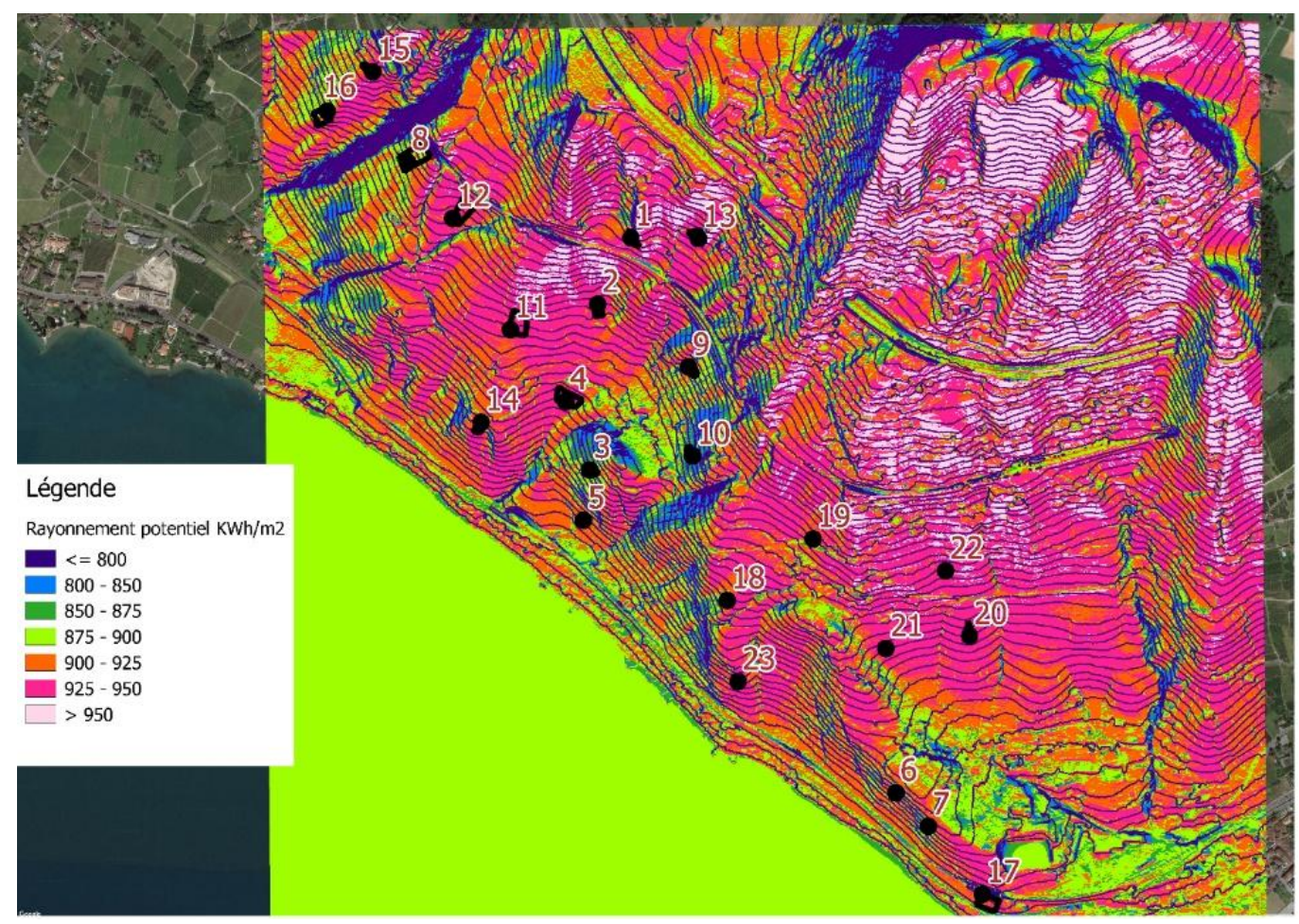

Figrue 3 - Radiation Map
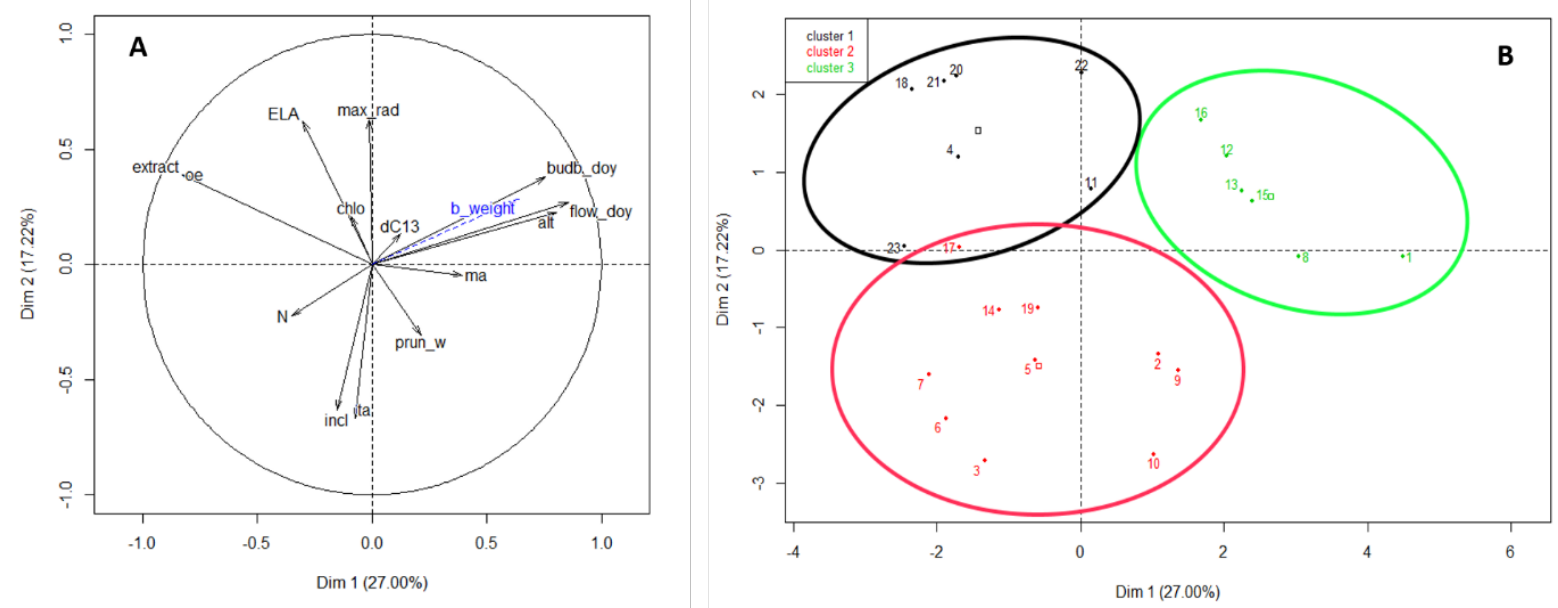

Figure 4- A: Principal component analysis of vegetative and biochemical and phenological data; b_weight: individual berry weigh, alt: altitude, budb_doy: day of budburst, flow_doy: day of flowering; dC13: delta 13C, prun_w: pruning weight, $\mathrm{N}$ : nitrogen content in must, ELA: exposed leaf area $/ \mathrm{kg}$, max_rad: potential solar radiation between $1^{\text {st }}$ April to $30^{\text {th }}$ September, chlo: chlorophyll content, oe: Sugar concentration in ${ }^{\circ}$ Oechsle; ma: malic acid $(\mathrm{g} / \mathrm{L})$, ta: tartaric acid $(\mathrm{g} / \mathrm{L}) \mathrm{B}$ : factorial map of plots groups by hierarchical clustering 

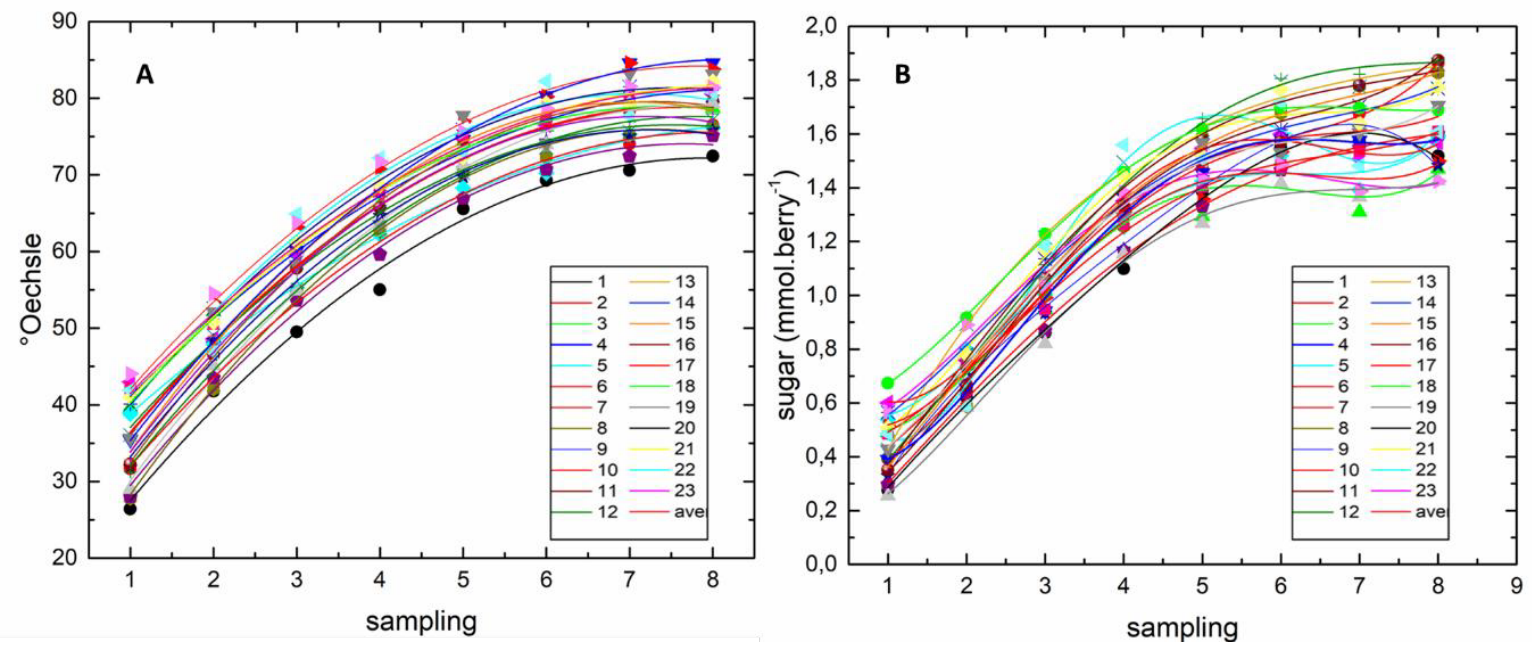

Figure 5: A: Sugar concentration evolution (in ${ }^{\circ}$ Oechsle) in all plots, fitted curvesfma are polynomial order 2 . B: Sugar accumulation pattern per berry of all plots (fits are polynomial order 4)

Acknowledgement: We would like to the thank the Fédération Vaudoise des vignerons (FVV) for funding the project as well as Thibault Verdenal, Pierre Durand and Cyril Toche for their help during sampling and sample processing.

Anderson, J.D., Jones, G. V., Tait, A., Hall, A. and Trought, M.C.T., (2012) Analysis of viticulture region climate structure and suitability in New Zealand. OENO One 46, 149.

Bondada, B.R., Matthews, M. a. and Shackel, K. a., (2005) Functional xylem in the post-veraison grape berry. J. Exp. Bot. 56, 2949-2957.

Burgos, S., Almendros, S. and Fortier, E., (2010) Facteurs environnementaux et phénologie de la vigne dans le canton de Genève. Rev. suisse Vitic. Arboric. Hortic. 42, 288-295.

Diakou-Verdin, P., Carde, J.-P., Gaudillère, J.-P., Barrieu, F., Ollat, N. and Moing, A., (2002) Grape berry development : A review. OENO One; Vol 36, No 3 J. Int. des Sci. la vigne du vinDO - 10.20870/oenoone.2002.36.3.970 .

Keller, M., Smith, J.P. and Bondada, B.R., (2006) Ripening grape berries remain hydraulically connected to the shoot. J. Exp. Bot. 57, 2577-2587.

Leeuwen, C. Van and Seguin, G., (2006) The Concept of Terroir in Viticulture. J. Wine Rearch 17, 1-10.

van Leeuwen, C., Tregoat, O., Choné, X., Bois, B., Pernet, D. and Gaudillére, J.P., (2009) Vine water status is a key factor in grape ripening and vintage quality for red bordeaux wine. How can it be assessed for vineyard management purposes? J. Int. des Sci. la Vigne du Vin 43, 121-134.

Letessier, I. and Marion, J., (2007) Etude des terroirs viticoles valaisans (Suisse). Etude géo-pédologique, partie générale, méthodologie. Etudes sols terroirs, Letessier-Marion, 38410 St-Martin d’Uriage, 123 p.

Ojeda, H., Deloire, a. and Carbonneau, a., (2001) Influence of water deficits on grape berry growth. Vitis 40, 
141-145.

Reynard, J.Ś., Zufferey, V., Nicol, G.C. and Murisier, F., (2011) Vine water status as a parameter of the « terroir $\gg$ effect under the non-irrigated conditions of the vaud viticultural area (switzerland). J. Int. des Sci. la Vigne du Vin 45, 139-147.

Tomasi, D., Gaiotti, F. and Jones, G. V., (2013) The Role of Landscape in the Productive Context and in the Quality of Prosecco Wine, in: The Power of the Terroir: The Case Study of Prosecco Wine. Springer Basel, Basel, pp. 235-248.

Zufferey, V., Pythoud, K., Letessier, I., Reynard, J.., Moncio, C. and Murisier, F., (2008) Etdues des terroirs viticoles suisses. Rev. suisse Vitic. Arboric. Hortic. 40, 367-374. 